\title{
Long-term durability of HT-PEM fuel cells based on thermally crosslinked polybenzimidazole
}

Søndergaard, Tonny ; Cleemann, Lars Nilausen; Becker, Hans; Aili, David; Steenberg, Thomas; Hjuler, Hans Aage; Seerup, Larisa; Li, Qingfeng; Jensen, Jens Oluf

Published in:

Journal of Power Sources

Link to article, DOI:

10.1016/j.jpowsour.2016.12.075

Publication date:

2017

Document Version

Peer reviewed version

Link back to DTU Orbit

Citation $(A P A)$ :

Søndergaard, T., Cleemann, L. N., Becker, H., Aili, D., Steenberg, T., Hjuler, H. A., Seerup, L., Li, Q., \& Jensen, J. O. (2017). Long-term durability of HT-PEM fuel cells based on thermally crosslinked polybenzimidazole. Journal of Power Sources, 342, 570-578. https://doi.org/10.1016/j.jpowsour.2016.12.075

\section{General rights}

Copyright and moral rights for the publications made accessible in the public portal are retained by the authors and/or other copyright owners and it is a condition of accessing publications that users recognise and abide by the legal requirements associated with these rights.

- Users may download and print one copy of any publication from the public portal for the purpose of private study or research.

- You may not further distribute the material or use it for any profit-making activity or commercial gain

- You may freely distribute the URL identifying the publication in the public portal 
Type of file: Supplementary Materials

Title: Long-term Durability of HT-PEM Fuel Cells Based on Thermally Cross-linked Polybenzimidazole

Tonny Søndergaard ${ }^{\text {a }}$, Lars Nilausen Cleemann ${ }^{\text {a }}$, Hans Becker ${ }^{\text {a }}$, David Aili ${ }^{\text {a }}$, Thomas Steenberg $^{\mathrm{b}}$, Hans Aage Hjuler ${ }^{\mathrm{b}}$, Larisa Seerup ${ }^{\mathrm{a}}$, Qingfeng Li ${ }^{\mathrm{a},}{ }^{*}$, Jens Oluf Jensen ${ }^{\mathrm{a}}$

${ }^{a}$ Department of Energy Conversion and Storage, Technical University of Denmark, Kemitorvet 207, DK-2800 Kgs. Lyngby, Denmark

${ }^{\mathrm{b}}$ Danish Power Systems Ltd., Egeskovvej 6C, DK-3490 Kvistgård, Denmark

*Corresponding author, e-mail: qfli@dtu.dk

Keywords: durability, polymer electrolyte membrane, fuel cell, polybenzimidazole, cross-linking, thermally cured

\section{S1 EIS experimental details}

Though there should be little to no difference between results measured by galvanostatic- as opposed to potentiostatic EIS, it was determined that galvanostatic EIS was the more favourable mode as is often the case for devices with low impedance $[1,2]$. The interference from inductance at high frequency was mitigated by ensuring that the applied cable and its positioning were fixed throughout each measurement. Also, the applied cable was shielded and its length was kept 
relatively short $(\approx 2 \mathrm{~m})[1,3,4]$. Magnetic coupling as a result of mutual inductance was minimised by twisting together the current leads. This reduces the magnetic field because that which is generated by current flowing in one direction is compensated by that which is generated from current flowing in the opposite direction. Furthermore, the effect of the residual magnetic field was minimised by also twisting together the potential leads. Ideally, residual interference should then affect both the sense- and reference electrode leads with an equal magnitude of inverse polarity effectively generating a common mode signal that does not affect the EIS measurement. Finally, the current leads were separated from the potential leads as much as possible since the intensity of the magnetic field is reduced with distance.

The choice of what amplitude to apply was made by trial and error before starting the experiment and with the use of other MEAs that had been manufactured in a similar manner. First, a low amplitude was applied which yielded very noisy results. By repeated iteration, increase of the amplitude led to noise reduction. However, at a certain point the recorded EIS spectra became different from that recorded using lower amplitudes; usually a change in the low frequency region was observed. Such a change signifies that the amplitude is too high, and a reduction was made accordingly.

Prior to start-up of each cell, a short circuit impedance measurement was made for the empty cell hardware at the operating temperature of the cells, i.e. including everything but the PTFE gas sealings and the MEA itself. This was done to estimate which part of the EIS response from an operating fuel cell could not be attributed to the MEA in question. These measurements were carried out by applying an alternating current signal of approximately $280 \mathrm{~mA}\left(200 \mathrm{~mA}_{\mathrm{RMS}}\right)$, and the resulting resistance of the cell hardware accounted for approximately $5-8 \%$ of the series resistance measured for MEAs at BoL. The short circuit series resistance measurements are only indicative and have not been corrected for in the presented data because they include contribution 
from an unrelated contact resistance, namely that between two flow plates. Furthermore, the stability of this resistance has not been verified, though it is reasonable to assume that it does not change much over the course of the experiment.

Small amounts of water could condense in the exhaust tubes during operation since they were not isolated. The amount of water that would be condensed at any given time was less than 0.5 $\mathrm{mL}$ and was solely observed in the tube for the cathode exhaust. This had discernible impact neither on the steady state performance nor on the polarisation curve behaviour. Though indiscernible from direct current measurements, this water condensation did result in noise during EIS measurements at frequencies that were characteristic to each individual cell. Therefore, the exhaust tubes were disconnected from the cell immediately before an EIS measurement and then reconnected once the measurement had been carried out.

It is clear from the EIS measurements that there are additional arcs at low frequency for sample PBI-4k4 and X-1k which indicates slight mass transport problems already from BoL. In turn, by transitorily increasing the gas flows of air and hydrogen by just a few $\mathrm{NmL} \mathrm{min}{ }^{-1}$, the low frequency arc for these cells was identifies as being due to mass transport limitation on the anode side; the low frequency arc decreased as the anode gas flow was increased. For sample PBI-4k4, the mass transport resistance increased slightly right up until the EoT, whereas the maximum mass transport limitation for sample X-1k seems to have occurred after about one week of operation. Seeing that the hydrogen gas flow is quite small to begin with, it is possible that a leak from the anode gas chamber can be the cause of the observed mass transport resistance during the current increase of EIS sampling. The phenomenon cannot necessarily be ascribed as being due to a significant difference in the MEAs. 
S2 Supplementary figures and tables

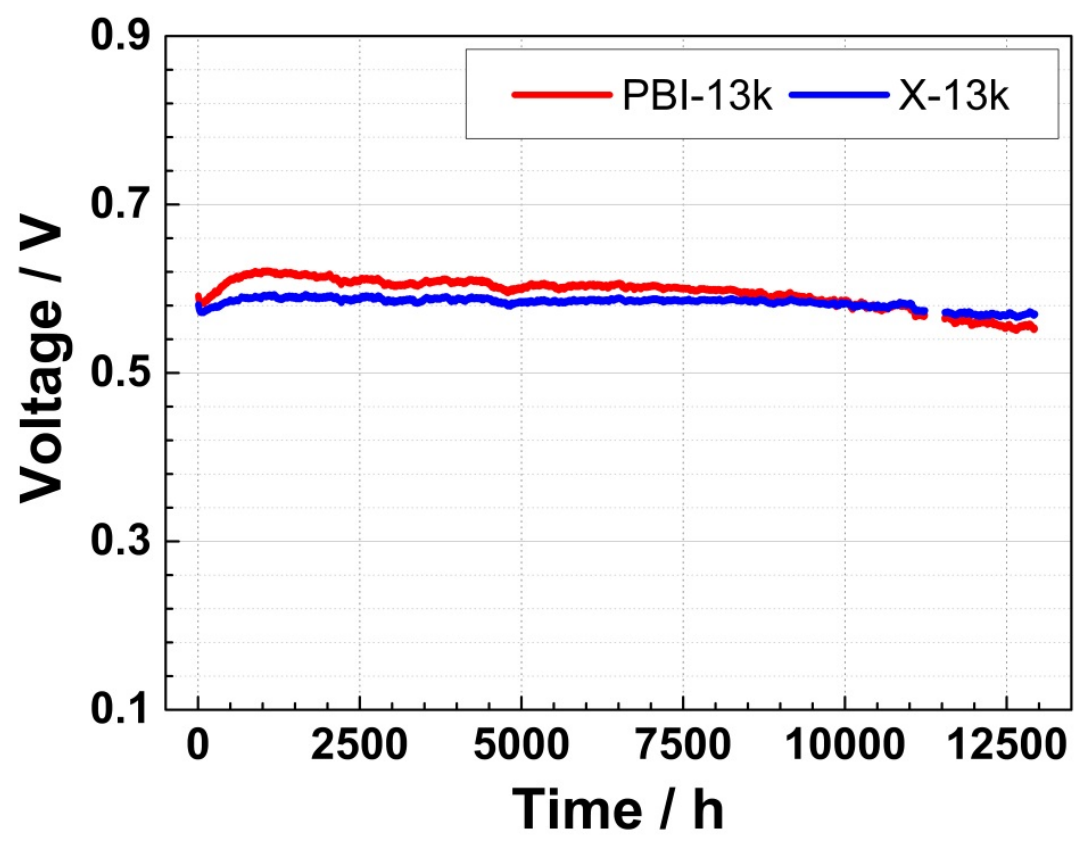

Figure S1 Steady state lifetime curves for MEAs based on linear $m$-PBI and cross-linked $m$-PBI operated at $160{ }^{\circ} \mathrm{C}, 200 \mathrm{~mA} \mathrm{~cm}{ }^{-2}, \lambda_{\text {air }}=4$, and $\lambda_{\mathrm{H} 2}=2$. This figure is intended for view in colour. 


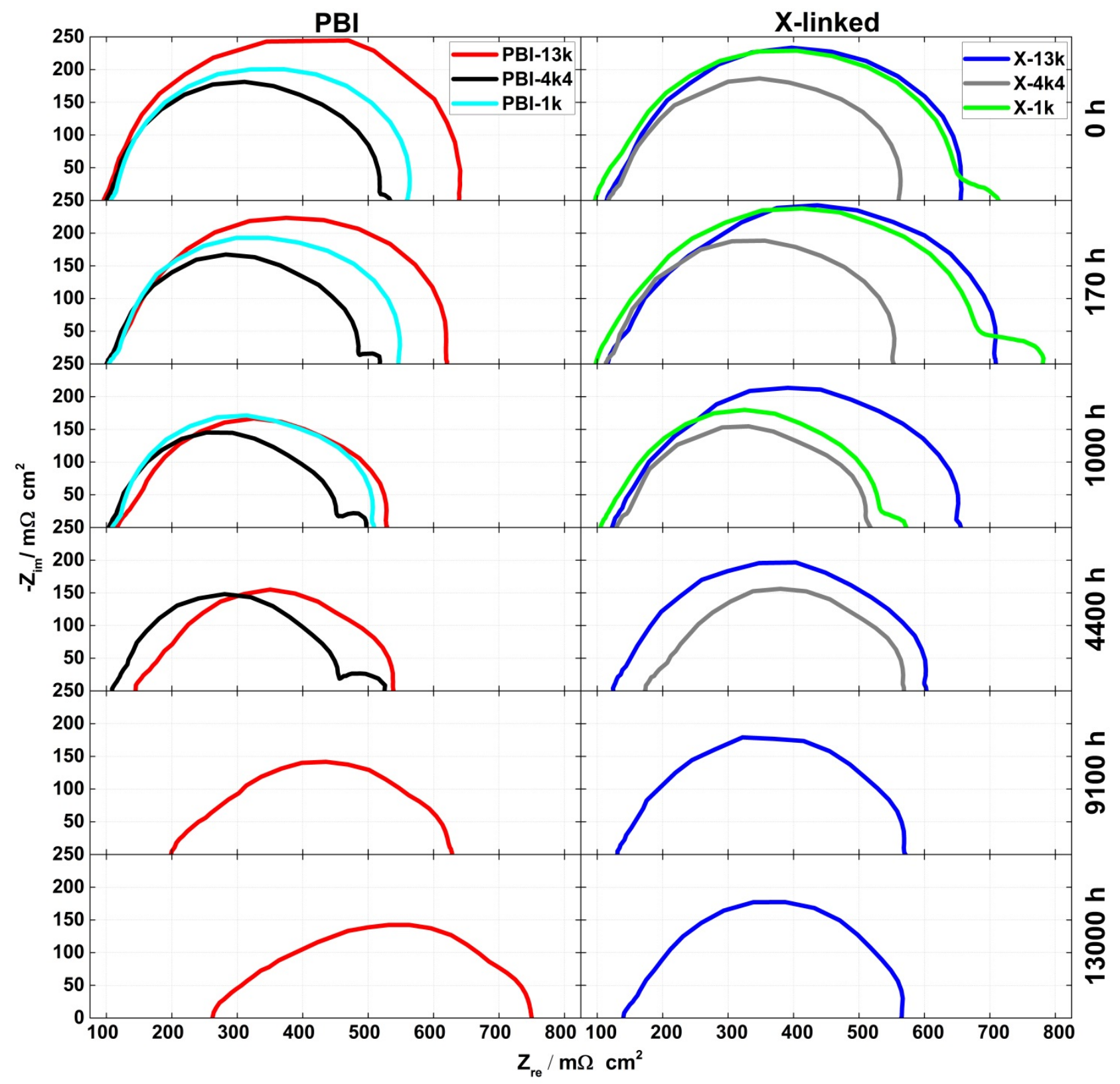

Figure S2 Comparison of EIS measurements over time for three MEAs based on linear $m$-PBI membranes (left) and for three MEAs based on cross-linked $m$-PBI membranes (right).

Interferences caused by noise have been masked. This figure is intended for view in colour. 


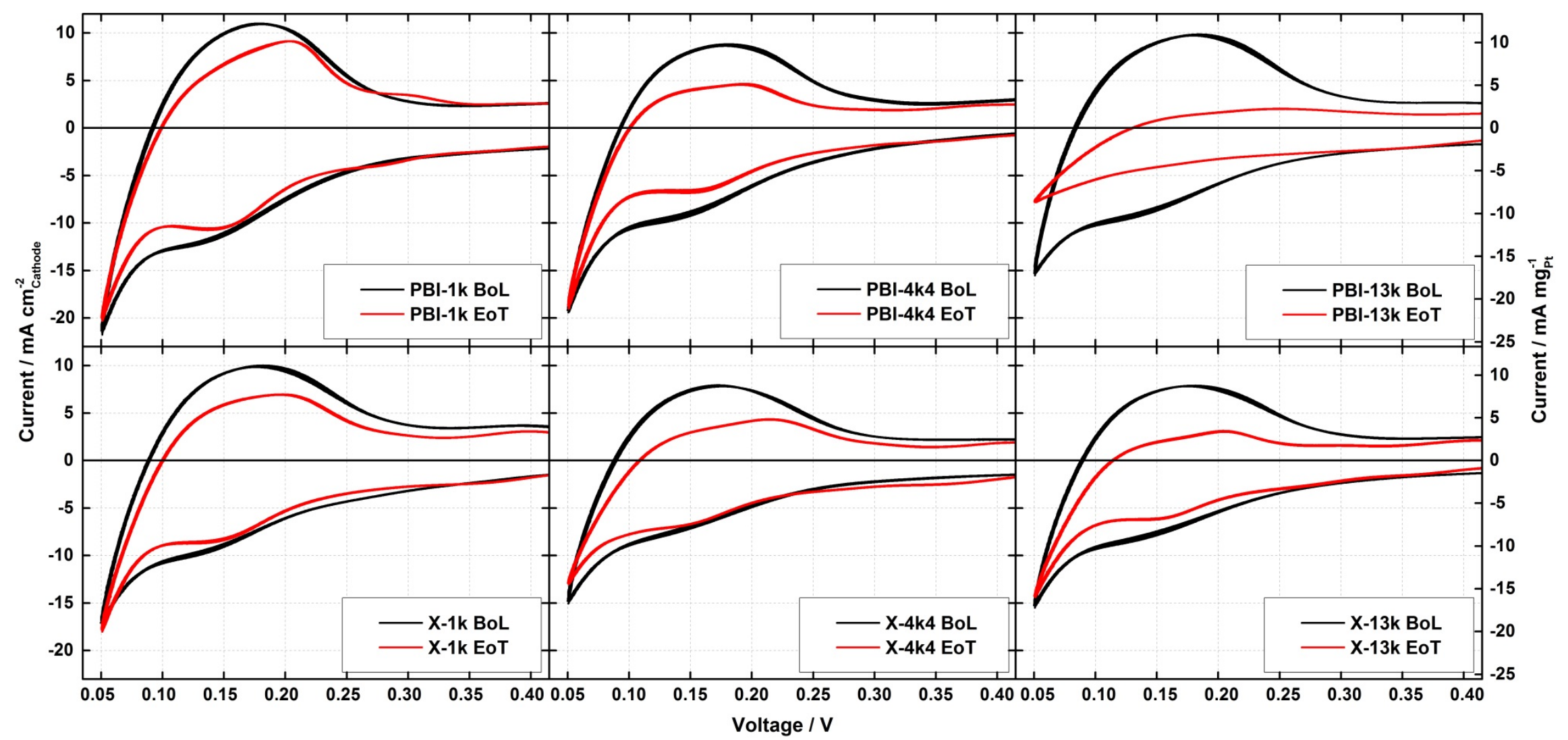

Figure S3 Average of 20 cyclic voltammograms at BoL (black) and EoT (red) of three MEAs based on linear $m$-PBI membranes as compared to three MEAs based on cross-linked $m$-PBI membranes. The thickness of the curve relative to that of the legend is indicative of the measurement stability as it represents the standard deviation in current and voltage between each set of 20 cycles. The maximum coefficient of variation is less than $3 \%$ of the average for each point. This figure is intended for view in colour. 


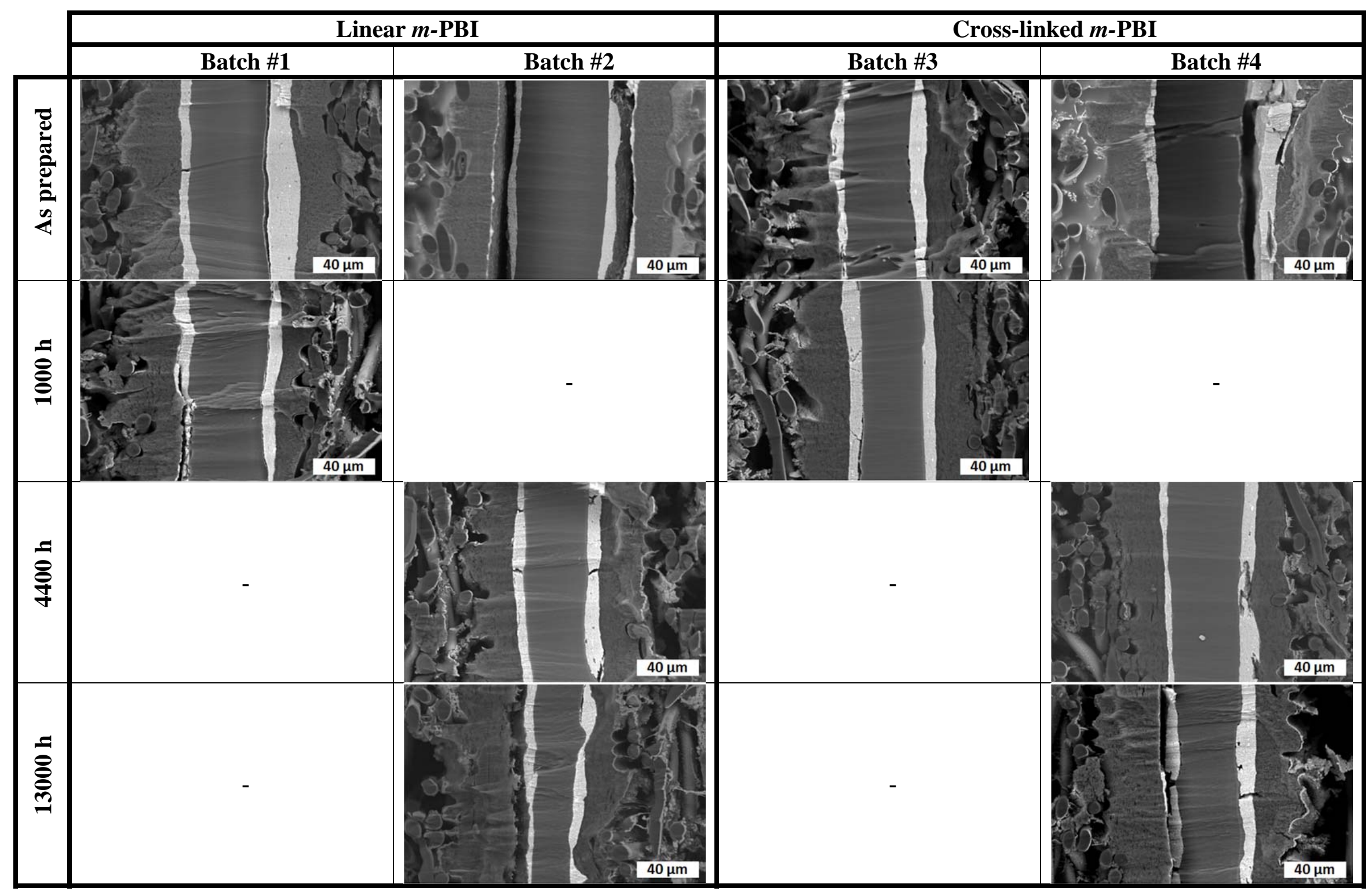


Figure S4 Cross-sectional backscatter electron images of MEAs based on linear m-PBI membranes (left) as compared to MEAs based on cross-linked $m$-PBI membranes (right) after the indicated duration of steady state operation, cf. sample names in Table 1 . All scale bars are $40 \mu \mathrm{m}$ and the cathode faces right in every case. 


\section{References}

[1] Gamrylnstruments Inc., Verification of low impedance EIS using a $1 \mathrm{mOhm}$ resistor, Technical note, http://www.gamry.com/assets/Application-Notes/Low-Impedance-EIS-on-1-mOhm-Resistor.pdf, 2011 (accessed 24.0816).

[2] X. Yuan, H. Wang, J.C. Sun, J. Zhang, Int. J. Hydrog. Energy, 32 (2007) 4365-4380.

[3] C.A. Schiller, Main error sources at AC measurements on low impedance objects, in: H.-J. Schäfer, C.A. Schiller (Eds.) Electrochemical Applications 1/97, Zahner-elektrik GmbH \& Co., Kronach, Germany, http://zahner.de/pdf/ea1997.pdf, 1997 (accessed 24.08.2016).

[4] Bio-logic Science instruments, Precautions for good impedance measurements, Application note \#5, http://www.bio-logic.info/potentiostat-electrochemistry-ec-lab/apps-literature/applicationnotes/impedance/, (accessed 24.08.16). 